\title{
Aproximación sociopragmática a las estrategias conversacionales de los adolescentes*
}

\author{
FRANCISCO JOSÉ ORTEGA SALAMANCA** \\ Institución Educativa Integrado de Cómbita - Boyacá, Colombia \\ frajorsal@hotmail.com
}

BELCY VICTORIA VARGAS CORTÉS ${ }^{* * *}$

Institución Educativa Técnica de Nobsa - Boyacá, Colombia

belcyvick@hotmail.com

Recepción: 25 de junio de 2016

Aprobación: 05 de septiembre de 2016

Forma de citar este artículo: Ortega Salamanca, F.J., \& Vargas Cortés, B.V. (2017). Aproximación sociopragmática a las estrategias conversacionales de los adolescentes. Cuadernos de Lingüística Hispánica, (29), 83-103. doi: http://dx.doi.org/10.19053/0121053X. n29.2017.5849

* Artículo de investigación enmarcado en la línea de Lenguaje y Sociedad, el cual evidencia los resultados preliminares del proyecto titulado Aproximación socio-pragmática a las estrategias conversacionales de los estudiantes de Grado Décimo en dos instituciones educativas, una de Cómbita y una de Nobsa, 2015.

** Licenciado en Ciencias de la Educación Español-Inglés. Especialista en Literatura y Semiótica- Investigación y Docencia y Magíster en Lingüística. Docente del área de Humanidades en la Institución Educativa Integrado de Cómbita - Boyacá, Colombia.

*** Licenciada en Ciencias de la Educación Español-Francés. Especialista en Lúdica y Desarrollo Social y Magíster en Lingüística. Docente del área de Humanidades en la Institución Educativa Técnica de Nobsa - Boyacá, Colombia. Código ORCID: orcid. org/0000-0003-0752-7289 


\section{Resumen}

Este artículo expone hallazgos de una investigación apoyada en referentes teóricos propios de la Sociopragmática, la cortesía y la descortesía, cuyo propósito fue identificar las estrategias conversacionales predominantes entre adolescentes de Grado Décimo de dos instituciones educativas de Nobsa y Cómbita (Boyacá, Colombia), para interpretar estrategias de camaradería presentes en sus conversaciones espontáneas. Se recurrió a un enfoque metodológico cualitativo, con base en el Análisis de la conversación, desde la Etnografía del habla. La investigación se cimentó en tres fases: de diagnóstico, de recogida de información y aplicación de instrumentos, y de análisis e interpretación del corpus obtenido. Los resultados evidenciaron estrategias conversacionales preferidas y fórmulas de tratamiento que usan los adolescentes en contextos informales, estas los identifican y les sirven para entablar cierto grado de afinidad en el grupo.

Palabras clave: Sociopragmática, eventos comunicativos, conversación coloquial, fórmulas de tratamiento, contexto informal.

\section{Socio-Pragmatic Approach to Teenagers' Conversational Strategies}

\section{Abstract}

This article presents the results of a research project supported in socio-pragmatic theoretical references, such as politeness and rudeness. Its main purpose was to identify the most common conversational strategies between tenth graders from educational institutions of Nobsa and Cómbita (Boyacá, Colombia), in order to interpret some of the comradeship strategies used by these students in their day-to-day conversations. A qualitative approach based on Conversational Analysis was implemented, coming from the field of Speech Ethnography. The research process was built upon three fundamental bases: the diagnosis, information gathering and implementation of instruments phase, and the phase of analysis and interpretation of the obtained data. The outcome revealed some of the most popular conversational strategies and treatment formulas used by the teenagers in informal contexts, which help them to establish a certain degree of fellowship amongst themselves.

Key words: Socio-pragmatics, Communicative Events, Informal Conversation, Treatment Formulas, Informal Contexts. 


\section{Approximation sociopragmatique aux stratégies conversationnelles des adolescents}

\section{Résumé}

Cet article expose des découvertes d'une recherche appuyée sur des référents théoriques propres de la Sociopragmatique, la courtoisie et l'impolitesse, dont le but était l'identification des stratégies conversationnelles prédominantes chez les adolescents des classes de première de deux institutions éducative de Nobsa et Cómbita (Boyacá, Colombie), pour interpréter des stratégies de camaraderie présentes dans leurs conversations spontanées. On a fait appel à une approche méthodologique qualitative, ayant comme base l'Analyse de la conversation, dès l'ethnographie de la parole. La recherche s'est appuyée sur trois phases: diagnostic ; récolte d'information et d'application des instruments ; et analyse et interprétation du corpus obtenu. Les résultats ont mis en évidence des stratégies conversationnelles préférées et des formules de traitement que les adolescents utilisent dans des contextes informels; celles-là constituent leur identité et leur sont utiles pour engager un certain degré d'affinité dans le groupe. .

Mots clés: Sociopragmatique, événements communicatifs, conversation colloquiale, formules de traitement, contexte informel.

\section{Aproximação sociopragmática às estratégias conversacionais dos adolescentes}

\section{Resumo}

Este artigo expõe descobertas de uma pesquisa apoiada em referentes teóricos próprios da Sociopragmática, a cortesia e a descortesia, cujo propósito foi identificar as estratégias conversacionais predominantes entre adolescentes do $2^{\circ}$ ano do Ensino Médio de duas instituições educativas de Nobsa e Cómbita (Boyacá, Colômbia), para interpretar estratégias de camaradagem presentes em suas conversações espontâneas. Recorreuse a um enfoque metodológico qualitativo, com base na Análise da conversação, desde a Etnografia da fala. A pesquisa baseou-se em três fases: de diagnóstico, de recolhida de informação e aplicação de instrumentos, e de análise e interpretação do corpus obtido. Os resultados evidenciaram estratégias conversacionais preferidas e fórmulas de tratamento que usam os adolescentes em contextos informais, estas os identificam e servem-lhes para estabelecer certo grau de afinidade no grupo.

Palavras chave: Sociopragmática, eventos comunicativos, conversação coloquial, fórmulas de tratamento, contexto informal. 


\section{Introducción}

En el contexto escolar, se observa que uno de los rasgos lingüísticos más relevantes en las interacciones comunicativas de los jóvenes, es el uso y aceptación de expresiones que, desde otros escenarios, son consideradas como descorteses y degradantes de la imagen social. Estas para los adolescentes aparentemente son estrategias conversacionales propias de su edad y tienen como finalidad el refuerzo de los lazos de camaradería y afinidad grupal, pero pueden constituirse, al mismo tiempo, en actos de trasgresión a las normas de convivencia social y amenazar la imagen del otro, cuando esta actitud es replicada en situaciones sociales más formales, como por ejemplo intercambios discursivos con adultos.

En relación con la cultura juvenil, esta investigación centra la atención en algunas estrategias conversacionales que incluyen manifestaciones verbales disfemísticas, al interior de su núcleo social. De esta forma, es importante definir cuáles son los estilos discursivos más usados por los jóvenes en sus conversaciones coloquiales. La aceptación de estas formas de habla se refleja en todos los ámbitos, especialmente en el medio escolar, en donde los estudiantes usan entre ellos expresiones malsonantes y peyorativas; actualmente, los adolescentes emplean fórmulas de tratamiento que establecen una brecha generacional que les sirve para demostrar independencia de la norma social preexistente. Sus hábitos lingüísticos se caracterizan por la innovación y expresividad, y por dar lugar al juego del lenguaje, sin importar que en él prevalezcan formas lingüísticas desaprobadas socialmente.

En este orden de ideas, como docentes y lingüistas, a los investigadores les interesa observar más de cerca las interacciones comunicativas de los jóvenes y el rol que juegan ciertos actos de habla marcados por la inclusión de enunciados soeces que se hacen oportunos en el momento en que se presentan. Al evidenciarse esta situación pragmática, surge la diferencia ideológica con los adultos, quienes consideran inadecuado el uso del lenguaje tabú y las palabras soeces. Rundblom (2013) reconoce que los adultos critican el lenguaje de los jóvenes, porque ostenta una pobreza lexical reflejada en el uso de gran cantidad de obscenidades y groserías.

Desde este punto de vista, se hace necesario analizar los fenómenos sociopragmáticos que se constituyen en estrategias de afinidad en las conversaciones coloquiales, carentes 
de interferencias de tipo diafásic $0^{4}$, lo cual repercute en el reconocimiento de registros diferentes a los del lenguaje formal y paralelos al discurso académico, pero igualmente efectivos para los fines de la interacción comunicativa.

Estos registros se han constituido, en las últimas décadas, en uno de los rasgos lingüísticos más relevantes en las interacciones comunicativas de los jóvenes y, en muchas ocasiones, son atestiguadas por los adultos, especialmente sus padres y sus docentes quienes, desde su escenario socio-cultural, consideran que estos discursos, cargados de "palabrotas" y maltratos verbales, no pertenecen al habla culta ni cumplen con las normas mínimas de urbanidad, constituyéndose así en manifestaciones descorteses.

No obstante, desde la Pragmática, disciplina que aborda el lenguaje en uso y en el contexto situacional en que ocurre, el uso de determinados lexemas no implica directamente una intención cortés o descortés sino que son los elementos contextuales los que definen el grado de afectación a la imagen social de los interlocutores. Para Anderson y Trudgill (1990), "no word or phrase is in itself bad. It is bad only in the eyes of those who evaluate and look at the language" (p. 35).

A raíz de esto, y considerando los aportes de Bravo (2003) en sus estudios sobre cortesía verbal, imagen social y contexto sociocultural, es pertinente revisar la relación estrecha entre estrategias conversacionales de afinidad grupal y disfemismo. Por consiguiente, el fortalecimiento de los lazos de camaradería entre las personas va de la mano con las actitudes lingüísticas involucradas en las interacciones comunicativas espontáneas y corresponde al investigador describir las categorías pragmáticas que se entretejen a la hora de compartir espacios de fraternidad y amistad. Para Bravo (2003), los eventos comunicativos están marcados en su elaboración por las circunstancias en que se da la conversación. En este sentido, la autora afirma:

En conversación, la imagen social se manifiesta en la actuación del "ego" frente al "alter" y en esta medida está unida a cómo se concibe una relación interpersonal en una circunstancia determinada. Los rasgos más predominantes de la imagen social forman parte de la identidad social pero no son la misma cosa. El concepto de imagen social abarca un sentimiento de pertenencia pero reduce su alcance a la actuación social de los interlocutores (p. 101).

4 El término hace referencia a las variaciones que sufre el lenguaje, de acuerdo con los diferentes tipos de registro lingüístico que se dan en cada situación y contexto comunicativos.

5 Ninguna palabra o frase es en sí mala, es mala solamente a los ojos de aquellos que evalúan y miran el lenguaje (traducción de los autores del presente artículo). 
De hecho, los jóvenes, en sus conversaciones espontáneas, aceptan sin restricción las estrategias conversacionales que fortalecen la afectividad y la confianza entre los hablantes. Además, en ciertas situaciones, ese tipo de lenguaje hace parte de sus fórmulas de tratamiento cotidianas. Entre los estudiantes de Grado Décimo, se observa que los enunciados peyorativos y las palabras vulgares han sufrido un proceso de resemantización que da origen a una nueva jerga juvenil aceptada y entendida solamente por ellos y estigmatizada por los adultos. Pese a que las expresiones disfemísticas están ahí y fueron concebidas para maltratar al otro, no son aceptadas por el imaginario colectivo, pero los jóvenes las usan para identificarse y fortalecer su afinidad con el núcleo social y no se sienten maltratados por ellas.

Con el fin de examinar este fenómeno lingüístico, se acude a la Etnografía del Habla, con base en el análisis de muestras orales de conversaciones entre estudiantes de Grado Décimo y encuestas a algunos de ellos y a docentes. Primero se trata de revisar las aportaciones teóricas sobre Sociopragmática, conversación coloquial y lenguaje juvenil. A continuación, se identifican las estrategias conversacionales usadas por los adolescentes de la muestra en sus interacciones cotidianas. Al final, se describen e interpretan para determinar el grado de aceptabilidad y las situaciones en las que ocurren estos fenómenos discursivos.

\section{El habla coloquial en los jóvenes: estrategias conversacionales}

Las interacciones comunicativas de los jóvenes, debido a su carácter informal, se desarrollan primordialmente alrededor de las conversaciones espontáneas, que desde la Pragmática, tal como lo mencionan Calsamiglia y Tusón (2002), son la forma prototípica de la comunicación verbal y la manera más típica en que las personas vivencian sus relaciones sociales. Es así que, las conversaciones cotidianas de los adolescentes se caracterizan por estar permeadas en gran medida por manifestaciones verbales estigmatizadas por los adultos por su carácter soez, inapropiado y malsonante, mientras que para los jóvenes son la consolidación de la afinidad, del sentido de pertenencia grupal y refuerzo de la camaradería.

Muchos autores han disertado acerca del lenguaje de los adolescentes de hoy. Uno de ellos es Vázquez (2007), quien afirma que:

El adolescente y el joven están consolidando una identidad personal y social, y el lenguaje les permite nombrarla y elaborarla, a su vez que las interacciones con otros a través de los discursos, les posibilita tomar referentes para su diferenciación como un grupo social diferente a los niños y a los adultos, y con una presencia como sujetos 0 actores sociales (p. 85). 
Entre los adolescentes, la forma más privilegiada de intercambio comunicativo y social, es la conversación coloquial que, según Briz (1997), "es una sucesión de más de dos turnos de habla no predeterminados, en la que existe un intercambio de papeles comunicativos (hablante-oyente-oyente-hablante) que favorece la tensión comunicativa" (p. 10). Es en la conversación coloquial donde mejor se identifica el refuerzo de los lazos de camaradería, propuesto por Lakoff (1973), y se relaciona con la afiliación estrecha que puede existir entre los interlocutores, demostrándose así la cercanía que guardan entre ellos y que los lleva a participar en cada uno de los actos lingüísticos de sus conversaciones espontáneas.

Cuando se dan estos actos de habla, cada enunciado puede adquirir connotaciones diferentes que no tienen que ver directamente con su significado literal. Las posibles interpretaciones dependen de factores contextuales tales como gustos, conocimientos, creencias, supuestos, opiniones, los cuales rodean el acto comunicativo mismo y son plenamente conocidos por los participantes. Muchos de estos factores se evidencian en las conversaciones coloquiales de los adolescentes del Grado Décimo, por ejemplo:

C: ¿Mucho jartar?

B: Qué gonorrea, marica. El día de las fiestas, gueón, estaba estaba rejarto

C: Yo estaba peor, guevón

A: En cambio, yo estaba en mi casita todo bieeen

B: $\downarrow$ ¿Sí? ¿Qué le dijo su cucho? Ese porrón es una camuflas mijo.

En el anterior fragmento de una conversación, tomado durante una de las horas de descanso de los estudiantes en el patio central de la institución, los jóvenes hablan coloquialmente sobre las fiestas de Nobsa y su participación en ellas. Es clara la forma como los interactuantes utilizan palabras soeces y malsonantes, con fines muy distintos al de la agresión a la imagen del otro.

El disfemismo, considerado por Díaz (2012) como "una palabra o expresión malsonante que hace referencia a los aspectos menos agradables de la realidad que designa" (p. 49), es usado en este fragmento de conversación como elemento de enlace que permite que la conversación fluya libremente y se mantenga la atención de los interactuantes. Esto es posible, sin lugar a dudas, debido al conocimiento mutuo de factores extralingüísticos que permean la interacción comunicativa. Para los adolescentes, ese tipo de expresiones funcionan como estrategias conversacionales de cohesión grupal que se dan de manera 
espontánea. Estos hallazgos concuerdan, en gran medida, con la afirmación de Briz (1998): "Conversar es comunicar cooperativamente y negociar estratégicamente un propósito con el otro" (p. 44). En este caso el propósito consiste en mostrar pertenencia al grupo, expresada en forma de manifestaciones lingüísticas.

\section{Aproximación socio-pragmática a las conversaciones colo- quiales de los adolescentes}

La pretensión de un enfoque socio-pragmático establece una consideración del uso del lenguaje en función de premisas socioculturales que determinan cómo utilizamos el discurso y para qué lo hacemos. Efectivamente, el contexto adquiere relevancia desde esta perspectiva. Para Leech (1983), la Sociopragmática es una línea de la Pragmática que permite el estudio de las "condiciones más específicas correspondientes a un determinado uso del lenguaje" (p. 54). Esta disciplina es la que estudia el uso de la lengua en su contexto de forma más determinada, teniendo en cuenta los componentes sociales y culturales.

Por lo tanto, la Sociopragmática está íntimamente ligada a la Pragmática. En palabras de Marek Baran (2010), esta relación radica en que "Si la pragmática se ocupa básicamente del estudio de los recursos lingüísticos particulares que proporciona una lengua dada para transmitir los diferentes tipos de ilocuciones, la sociopragmática debe, de igual modo, analizar cómo las conceptualizaciones de tipo social o cultural determinan el uso lingüístico" (p. 119).

Queda claro que el habla de los individuos está influenciada por su relación con el contexto, con respecto a sus posiciones sociales, su familiaridad, así como con la gravedad de la imposición expresada por el acto de habla. De acuerdo con cada grupo social, las estrategias conversacionales de los hablantes se presentan desde los discursos propios de esa comunidad. Además, las comunidades lingüísticas no se caracterizan simplemente por compartir la forma general de una lengua, sino que están delimitadas por otros factores sociales. En palabras de Hymes et al. (citados por Duranti, 1998):

El supuesto sobre el que se apoya el análisis del uso lingǘstico en eventos comunicativos es que la comprensión de la forma y del contenido de la conversación diaria implica, en sus distintas manifestaciones, la comprensión paralela de la actividad social en la que el habla tiene lugar. (p. 261).

Las comunidades de habla se organizan alrededor de sistemas locales de conocimiento y conducta social. Tal es el caso de los adolescentes quienes están en una búsqueda continua de una identidad que los diferencie de los adultos y de los niños y se sirven de formas de comunicación particulares que se alejan, en alguna medida, de 
la norma estándar de la lengua. En este afán por establecer su propia jerga, los jóvenes prefieren usar expresiones disfemísticas, y estrategias conversacionales que, desde otros escenarios, son consideradas como inapropiadas.

En esta investigación, los adolescentes de los grados décimos, en sus interacciones lingüísticas espontáneas, se expresan libremente haciendo caso omiso de la visión rígida y dogmática de la cortesía promulgada por los adultos. Por tanto, no es de extrañar que estos jóvenes también usen ciertas expresiones ( $\operatorname{tacos}^{6}$ y groserías) que a la luz de los estudios de la cortesía son poco aceptadas, pero que hacen parte del trato entre pares y en ocasiones se alejan del habla estándar de los adultos. Así, los muchachos "marcan su territorio lingüístico" y, únicamente en contextos de camaradería, estos actos de habla actúan como elementos de cohesión en su nicho social.

\section{Metodología}

El estudio de las estrategias conversacionales juveniles se desarrolla dentro del marco de la Etnografía de la comunicación, a partir del Análisis Conversacional, puesto que se trata del análisis de las formas lingüísticas propias de una comunidad de habla y que se presentan en el momento mismo de la interacción comunicativa. Respecto al enfoque metodológico aplicado aquí, Duranti (1988) afirma que:

La Etnografía del Habla (EH) estudia el uso del lenguaje tal y como se presenta en la vida cotidiana de una comunidad lingüística concreta. Su método es etnográfico, pero se acompaña de técnicas desarrolladas en otras áreas de estudio, como la pragmática, el análisis de la conversación, la poética y la historia. Sus contribuciones teóricas se aglutinan en torno al estudio del discurso en situación, es decir, se considera que la actuación lingüística es el lugar donde se enlaza la relación entre el lenguaje y el orden sociocultural. (p. 253).

En relación con la pertinencia de este método, Sacks, Schegloff \& Jefferson (citados por Tusón, 2002) afirman que: "El análisis de la conversación se propone revelar de qué manera los aspectos técnicos del intercambio verbal se constituyen en los recursos estructurados, organizados socialmente, por medio de los cuales los participantes realizan y coordinan actividades hablando-en-interacción" (p. 134).

Entre los instrumentos aplicados para la presente investigación, además de las encuestas a docentes y estudiantes, se le dio primordial importancia a las grabaciones espontáneas de audio y video, de conversaciones informales en actividades fuera de las aulas (descansos, encuentros deportivos, entre otros). Estos permitieron conocer, a

6 Concepto propio del Español peninsular para referirse a los términos grotescos y vulgares. 
través del análisis de ciertas categorías pragmáticas específicas, aspectos de la vida de los adolescentes, tales como su forma de hablar, sus creencias, sus sentimientos, su ideología y su interacción.

\section{Análisis de resultados: Estrategias conversacionales de afini- dad grupal}

Como se ha dicho anteriormente, las formas expresivas propias del habla juvenil emergen como un mecanismo de los adolescentes para definir su lugar en la sociedad y demostrar su rebeldía frente a los parámetros establecidos por los adultos. Mitkova (2009) enfatiza la informalidad que reviste el estilo de habla juvenil en su cotidianidad: "La interacción entre jóvenes que se produce de forma oral en conversaciones informales y espontáneas no tiene finalidad específica ni predeterminada. Sirve, sobre todo, para mantener y reforzar el contacto social, para estrechar los vínculos interpersonales existentes" (p. 24).

Teniendo en cuenta lo anterior, no es extraño escucharlos a menudo usando expresiones como: hijueputa, sapo, bobo, perro, parcero, mamita, gay, nero, gonorrea, loca, pichurria, baboso (a), mijo, entre otras. Esta constante ya ha sido estudiada por Zimmermann (2002) quien afirma que los jóvenes consideran ser más directos y sinceros para interactuar con sus pares, sin sentir afectada su imagen o la de los oyentes por el uso de este lenguaje tabuizado y disfemístico.

La siguiente tabla refleja los resultados de la investigación en relación con las estrategias conversacionales más usadas por los estudiantes de Grado Décimo de las instituciones educativas Técnica de Nobsa e Integrado de Cómbita, en sus conversaciones coloquiales. 
Tabla 1. Categorías de análisis

\begin{tabular}{|c|c|c|c|}
\hline \multicolumn{2}{|c|}{$\begin{array}{c}\text { ESTRATEGIAS } \\
\text { CONVERSACIONALES } \\
\end{array}$} & \multicolumn{2}{|r|}{ INDICADORES } \\
\hline \multicolumn{2}{|c|}{ Fórmulas de tratamiento } & \multicolumn{2}{|c|}{ Se dirige al interlocutor mediante un pronombre o sintagma nominal } \\
\hline \multicolumn{2}{|c|}{ - Expresiones fijas } & \multicolumn{2}{|c|}{$\begin{array}{l}\text { Se dirige al interlocutor mediante unidades lingüísticas fijas: A: } \uparrow \text { Ole panuchas.//... A: Ole } \\
\text { nitrochal }\end{array}$} \\
\hline \multicolumn{2}{|c|}{ - Apelativos } & \multicolumn{2}{|c|}{$\begin{array}{l}\text { Se llama la atención del oyente mediante determinadas expresiones nominales: A: Bueno } \\
\text { marica, ise vieron ayer protagonistas? .. B: Lástima marica... (Pausa) pero la Gabi }\end{array}$} \\
\hline \multicolumn{2}{|c|}{ - Apodos } & \multicolumn{2}{|c|}{$\begin{array}{l}\text { Se dirige al interlocutor mediante sobrenombres: C: } \uparrow \text { Paisa, venga (se vuelve a involucrar } \\
\text { "Távalo") B: } \ \text { (cantando) Távalo, / dábalo, dábalo... }\end{array}$} \\
\hline \multicolumn{2}{|c|}{ Ironía } & \multicolumn{2}{|c|}{ Expresa un enunciado queriendo significar algo distinto } \\
\hline \multicolumn{2}{|c|}{ Humorística } & \multicolumn{2}{|c|}{$\begin{array}{l}\text { Se usan enunciados irónicos para darle un toque de jocosidad a las conversaciones espontáneas: } \\
\text { B: y no ve que apenas se dieron el beso, ide una, p marica la voltió! ¿Cierto? Y̌ Y y dele, y dele, } \\
\text { y dele [risas] }\end{array}$} \\
\hline \multicolumn{2}{|c|}{ Inferencial } & \multicolumn{2}{|c|}{$\begin{array}{l}\text { Se profieren enunciados irónicos que requieren de un proceso de ostención inferencial para ser } \\
\text { comprendidos por los interlocutores: } 148 \mathrm{~A}: \ddot{\Upsilon} \text { Todas esas viejas, las viejas son ricas allá mano }\end{array}$} \\
\hline \multicolumn{2}{|c|}{ Ecoica } & \multicolumn{2}{|c|}{$\begin{array}{l}\text { Responde a una expresión irónica con otra del mismo tipo: A } \uparrow \ddot{\Upsilon} \text { Que bobo tan bobo B } \uparrow \ddot{Y} \\
\text { Qué, qué miraba, } A \uparrow \dddot{\Upsilon} \text { qué miraba usté, gonorrea (risas) }\end{array}$} \\
\hline \multicolumn{2}{|c|}{ Mitigadores } & \multicolumn{2}{|c|}{$\begin{array}{l}\text { Se suaviza una expresión descortés incluyendo una expresión atenuadora: D: Ү̈ La Diana } \\
\text { aguanta, y eso que esa es fea, guevón. }\end{array}$} \\
\hline \multirow{8}{*}{$\begin{array}{l}\mathrm{A} \\
\mathrm{t} \\
\mathrm{e} \\
\mathrm{n} \\
\mathrm{u} \\
\mathrm{a} \\
\mathrm{d} \\
0 \\
\mathrm{r} \\
\mathrm{e} \\
\mathrm{s}\end{array}$} & \multirow{4}{*}{$\begin{array}{l}\text { Lexicales } \\
\text { Se usan } \\
\text { palabras que } \\
\text { suavizan la } \\
\text { agresión a la } \\
\text { imagen }\end{array}$} & 1. Diminutivos & $\begin{array}{l}\text { Se reduce la carga del enunciado mediante la adición de sufijos: -ito, } \\
\text {-ita, -icillo,:A: } \uparrow \mathrm{m} \text { Todo chiquito tiene culo }\end{array}$ \\
\hline & & 2. Frases de cortesía & $\begin{array}{l}\text { Se usan términos corteses estereotipados para mantener la cordialidad } \\
\text { en la conversación. }\end{array}$ \\
\hline & & $\begin{array}{l}\text { 3. Construcciones } \\
\text { adverbiales }\end{array}$ & $\begin{array}{l}\text { Se incluyen adverbios de modo, cantidad y frecuencia, entre otros, para } \\
\text { disminuir la carga ilocutiva de un enunciado. C: m Yo estaba peor, } \\
\text { guevón }\end{array}$ \\
\hline & & $\begin{array}{l}\text { 4. Construcciones } \\
\text { verbales }\end{array}$ & $\begin{array}{l}\text { Se incluyen expresiones verbales como las del subjuntivo, el pretérito } \\
\text { imperfecto, el futuro y aún los verbos modales, para evitar enunciados } \\
\text { tajantes: } \mathrm{B} \uparrow \mathrm{m} \text { [iHey! Ve, a la próxima, focalízate y llamaaame] }\end{array}$ \\
\hline & \multirow{4}{*}{$\begin{array}{l}\text { Sintácticos } \\
\\
\text { Se construyen } \\
\text { oraciones } \\
\text { completas } \\
\text { que sirven } \\
\text { para atenuar } \\
\text { la amenaza a } \\
\text { la imagen del } \\
\text { interlocutor. }\end{array}$} & $\begin{array}{l}\text { 1. Expresiones } \\
\text { impersonales, } \\
\text { indefinidas e } \\
\text { interrogativas }\end{array}$ & $\begin{array}{l}\text { Se usan formas impersonales, indefinidas e interrogativas en los } \\
\text { enunciados con el fin de ser cautelosos. }\end{array}$ \\
\hline & & $\begin{array}{l}\text { 2. Construcciones } \\
\text { en pretérito } \\
\text { imperfecto o en } \\
\text { futuro }\end{array}$ & $\begin{array}{l}\text { Se usan oraciones en imperfecto o futuro para ser indirecto en una } \\
\text { exhortación, consejo o mandato. }\end{array}$ \\
\hline & & $\begin{array}{l}\text { 3. Nosotros con } \\
\text { valor inclusivo }\end{array}$ & Se incluye a sí mismo como receptor de la agresión a la imagen. \\
\hline & & 4. Circunloquios & $\begin{array}{l}\text { Se usan enunciados con demasiados rodeos para mitigar la amenaza } \\
\text { potencial a la imagen del interlocutor: A: } \leftrightarrow \mathrm{m} \text { Ay, pero pa' que se } \\
\text { pone a peliar por viejas, guevón. Usté también tiene guevo... [Y̛ Usté } \\
\text { es como bobo] }\end{array}$ \\
\hline \multicolumn{2}{|c|}{ Insulto } & \multicolumn{2}{|c|}{ Se usan términos o expresiones cuya finalidad es ofender al otro. } \\
\hline \multicolumn{2}{|c|}{ Receptor presente } & \multicolumn{2}{|c|}{$\begin{array}{l}\text { Se usan deliberadamente enunciados ofensivos en presencia del destinatario: A: } \leftrightarrow \text { Coma } \\
\text { mierda Nana. }\end{array}$} \\
\hline \multicolumn{2}{|c|}{ Receptor ausente } & \multicolumn{2}{|c|}{$\begin{array}{l}\text { Se usan enunciados ofensivos en ausencia del destinatario: A: } \\
\text { es severo gusano, gueón }\end{array}$} \\
\hline
\end{tabular}

Fuente: Ortega \& Vargas (2015) 
No se puede negar que algunas de estas expresiones son también utilizadas con fines de agresión a la imagen social del otro, cuando los contextos y las circunstancias socioculturales lo ameritan. Esta dicotomía pragmática es reconocida por Culpepper (citado por Bernal, 2007), quien afirma que existe una descortesía burlesca o mock impoliteness, la cual no se constituye en amenaza a la imagen, cuando la intención del que realiza la actividad no es la de ofender. Del mismo modo, Kienpointner (1997) establece que estas estrategias conversacionales sirven para crear un ambiente relajado entre los interactuantes. ${ }^{7}$

En cuanto a las respuestas allegadas por los estudiantes en lo atinente a la agresión de su imagen por parte de sus compañeros, las expresiones lingüísticas que más hieren la susceptibilidad del agredido son los insultos dirigidos a su familia y los ataques directos a la autoestima:

¿En qué momento las expresiones que usas como camaradería con los demás compañeros te ofenden?

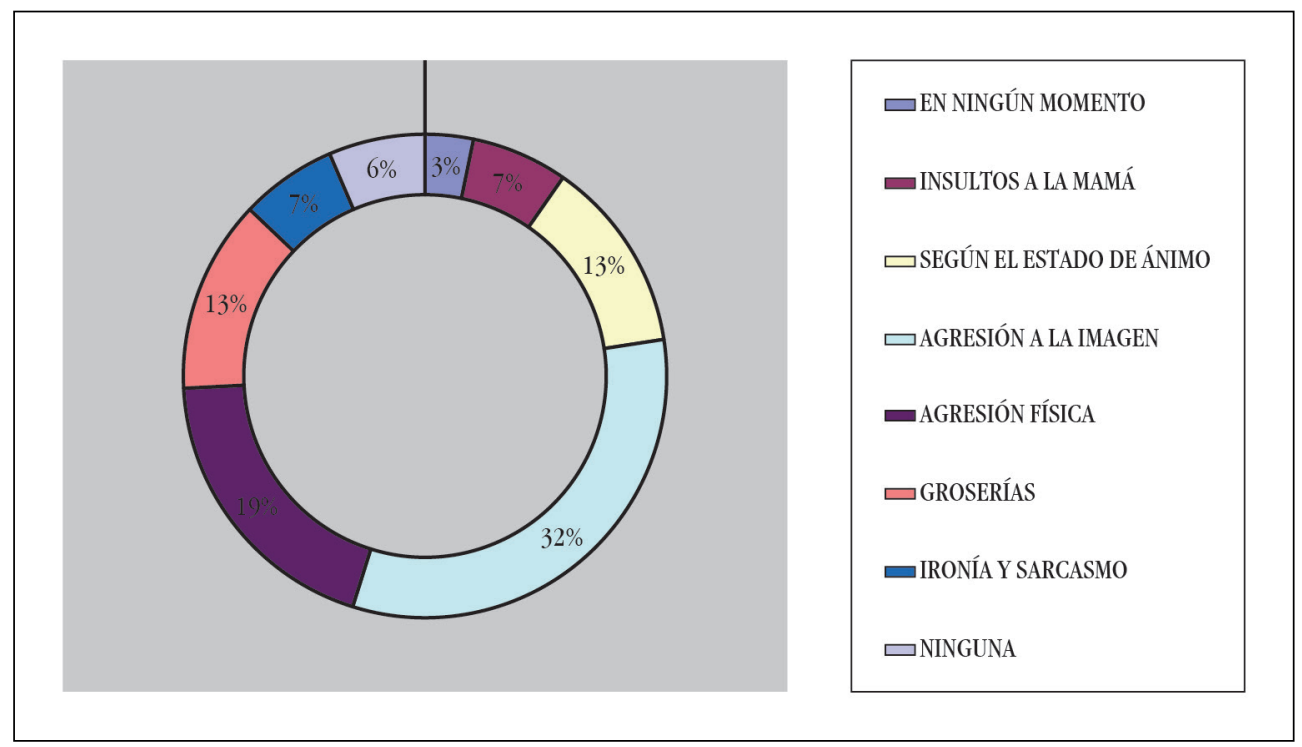

Figura 1. Muestra resultados de encuesta a estudiantes

Fuente: Ortega \& Vargas (2015)

$7 \quad$ Ese ambiente relajado es el que generalmente tratan de promover los jóvenes en sus conversaciones coloquiales. 
En sus interacciones comunicativas los hablantes usan expresiones lingüísticas que sirven para dirigirse la palabra entre sí, para iniciar la conversación o para insinuar cambios de turno, entre otras finalidades. A esas formas lingüísticas se les clasifica como fórmulas de tratamiento y entre ellas se encuentran unas de carácter fijo como los saludos, las expresiones de cortesía y los títulos, entre otras, y unas que pueden variar de acuerdo con diversas circunstancias pragmáticas.

Es importante recalcar, sin embargo, que los adolescentes se adaptan en sus fórmulas de tratamiento a las circunstancias de cada intercambio verbal. Es por esto que, en sus conversaciones formales, por ejemplo con docentes, su manera de expresarse es más cercana a la lengua estándar y tratan de evitar el uso de su jerga ${ }^{8}$

El estudio sociopragmático del que se da cuenta aquí, también permitió evidenciar que, entre las diversas fórmulas de tratamiento existentes, los adolescentes dan mayor preponderancia a los apelativos, las expresiones fijas y los apodos, siendo los primeros la estrategia comunicativa más repetida en sus discursos, incluyendo términos como mijo, hijueputa, perro y pichurria, entre otros.

La ironía es otra de las estrategias de afinidad y pertenencia grupal usadas por los estudiantes de la muestra, que consiste en la expresión de un pensamiento en un enunciado, cuyo nivel semántico refleja una idea diferente e incluso contraria a lo que pretende expresar el emisor. El contexto en el que se presenta el enunciado irónico debe aportar los indicios que permitan la desambiguación del mensaje.

El oyente, entonces, realiza un proceso de decodificación que Casas (2004) explica:

[...] el oyente transforma la información que considera fidedigna (esto es, de bona fide) en comunicación de non bona fide, al percatarse de la intención humorística del texto. Es decir, el oyente procesa el texto, nota la violación del principio de cooperación de buena fe, retrocede mentalmente y reinterpreta el texto como una broma. (p. 123).

Entre hablantes en edad adolescente, la aparición de enunciados irónicos en conversaciones coloquiales es bastante común. Generalmente entre miembros de un grupo con afinidad social, son utilizados para darle un toque de humor a la conversación, llegando en pocas ocasiones a convertirse en expresiones de burla $\mathrm{u}$ ofensa hacia el ironizado.

8 Rodríguez (citado por Rundblom, 2013) sostiene que: "el uso de las diferentes expresiones tiene que ver, entre otras cosas, con la lealtad con el propio grupo. De hecho, los jóvenes elijen diferentes palabras, dependiendo de la situación. De esta manera, se puede mostrar la pertenencia a un cierto grupo, y con la esperanza de identificarse y de diferenciarse de otros, eligen una expresión determinada" (pp. 35-36). 
Desempeñan principalmente un papel humorístico que permite mantener relaciones de confianza y solidaridad entre los interactuantes. Alvarado Ortega (2005) define la ironía como: "[...] un proceso pragmático en el que el significado viene dado por el contexto en el que se produce y por la respuesta que causa en su oyente" (p. 43). La interpretación de la ironía por parte del destinatario puede desencadenar efectos tales como placer, complicidad o burla como consecuencia de su carácter lúdico-semántico. Por tanto, la manifestación de la ironía verbal tolera en los interlocutores la creación de juegos con el lenguaje, los cuales tienen como finalidad suscitar, en alguna parte de la audiencia, un efecto humorístico.

Por ejemplo, en la siguiente intervención de una grabación espontánea, el hablante B expresa su disgusto en relación con las fiestas que se realizan en su municipio. Los hablantes dan a entender que, a pesar de tratarse de un evento pensado para que la gente se divierta, en las fiestas suceden constantemente hechos violentos y, por lo tanto, es mejor no participar en esas celebraciones:

$B \downarrow \ddot{Y}$ Pa que ir, pa que nos den cuchillo.

$A \leftrightarrow$ Esa cp plaga hijueputa es realzada, ¿no?

$B \leftrightarrow$ Realzados los malparidos

El papel de la ironía en este caso es el de criticar una actitud generalizada en las personas que participan de las festividades a la que se alude. Afirma Kočman (2011) que "La severidad y la justificación de las críticas deciden si el motivo del hablante es salvar su cara o la del oyente" (p. 169).

La estrategia conversacional ironía requiere aquí de un proceso de ostensión inferencial, para ser decodificada por el destinatario y cumple el papel de salvaguardar la imagen positiva del hablante y afectar la de aquellos de quienes se habla (en este caso, la gente que participa de las fiestas), dando a entender que el emisor no hace parte de aquellos que "dan cuchillo". Gracias a la relación de camaradería entre los hablantes, las expresiones disfemísticas son aceptadas y utilizadas por los miembros del núcleo social en sus eventos comunicativos espontáneos.

En cuanto a la estrategiadel insulto, las conversaciones coloquiales de los adolescentes son un medio rico en esta clase de actuaciones lingüísticas. A pesar de ello, se debe tener en cuenta que en los intercambios verbales espontáneos, la mayoría de los insultos pertenecen a lo que Labov (1972) denominó "insultos rituales" y las demás manifestaciones insultantes van dirigidas, en su mayoría, a terceros ausentes de la conversación. Fuentes (2008) afirma que el uso del insulto puede tener como finalidad: "Crear una relación social agradable, positiva con la imagen del otro: entonces atenúa, reduce al eufemismo. Si el grupo social se 
caracteriza por un alto grado de familiaridad o confianza, utiliza el tabú sin carga negativa, con efecto anticortés" (p. 19).

Es así que, en una encuesta aplicada a estudiantes como parte de las etapas de investigación, se observa la presencia de estrategias conversacionales con cierto grado de agresividad verbal:

¿Cuáles expresiones coloquiales o de camaradería escuchas más entre tus compañeros?

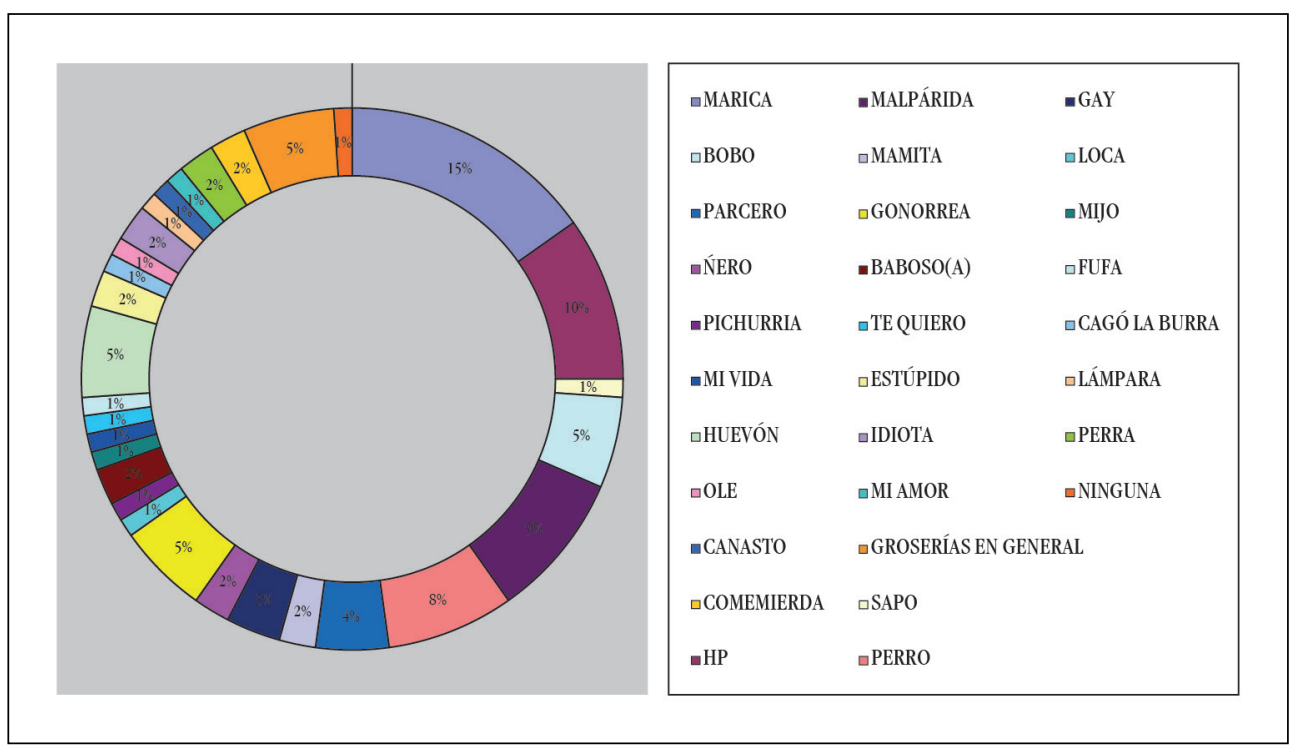

Figura 2. Muestra resultados de encuesta a estudiantes

Fuente: Ortega \& Vargas (2015)

Las respuestas permiten notar la familiaridad con la que los jóvenes de la muestra usan y aceptan, como parte de sus hábitos lingüísticos, palabras soeces, ofensas y groserías, que se convierten en muestras de afinidad y pertenencia a su grupo social. Son las circunstancias del evento comunicativo las que afectan la clase de registro lingüístico que usan los hablantes en una situación determinada. Los interlocutores de una comunidad específica están en capacidad de interpretar los enunciados de los demás hablantes. Esa capacidad proviene del contacto con el entorno social y de las experiencias comunicativas previas compartidas, en parte, con otros.

En un intercambio comunicativo la cercanía e identidad grupal entre los hablantes son factores socioculturales que inciden en el uso de ciertos actos de habla y facilitan una comunicación más efectiva. Por ejemplo, en las siguientes intervenciones, tres estudiantes 
de grado décimo utilizan términos disfemísticos en forma de apelativos nominales, de uso cotidiano en su entorno social y escolar, para mantener la continuidad del diálogo. En las intervenciones no se revela en ningún momento contrariedad por escuchar dichas expresiones, sino que estas hacen parte de sus conversaciones coloquiales:

C: Y que le iba a decir yyyy...

\section{$B$ : Ab, yo no sé guevón}

A: ¿y el otro año va ir al paseo?

B: y el otro año sí marica

Hernández Flores (2006) reconoce que el contexto sociocultural comprende "comportamientos, actitudes y valores que son conocidos, aceptados y practicados en una comunidad de hablantes" (p. 96). De acuerdo con esta afirmación, el contexto sociocultural abarca los factores extralingüísticos que acompañan un enunciado. El hablante de una lengua está capacitado para inferir e interpretar la información emitida por otros y reconocer en ella las implicaturas que le permiten identificar las intenciones comunicativas, gracias a los recursos que le aportan sus experiencias lingüísticas. En este caso, los jóvenes comprenden que esas palabras, marcadas como palabras tabú, no se emiten con intención ofensiva sino que son formas de apelación entre amigos. En relación con estos aspectos, en las interacciones comunicativas de los adolescentes, Hernes (2011) manifiesta: "La interpretación y el uso de las palabras tabúes varían de una persona a otra, de una región 0 un país a otro. También tienen importancia factores como: la cultura y la religión, la edad de las personas, el sexo y la clase social" (p. 25).

Evidentemente, en el contexto de las conversaciones coloquiales entre adolescentes, las estrategias conversacionales incluyen expresiones y términos tabuizados, ${ }^{9}$ los cuales generalmente cumplen una función intensificadora de carácter positivo o negativo. Para el caso de los jóvenes de grado décimo, usan expresiones como: mucha gonorrea, qué güevonada, ser una mierda, no sea marica, hijueputa, entre otras. La inclusión de estas frases en forma espontánea, y al interior de su círculo social, no implica la intención de afectar directamente la imagen del interlocutor, sino la de valorar una situación o llamar la atención sobre algún dato o situación particular.

9 Estos vocablos incluyen todos aquellos términos vetados por la sociedad, puesto que revisten un carácter disfemístico y hacen referencia, por ejemplo, a todo lo relacionado con la sexualidad. Hay que tener en cuenta que, de acuerdo con Chamizo (2008), "Los resultados de las más recientes investigaciones sobre el tabú y el lenguaje parecen haber dejado bastante claro que el tabú lingüístico está presente en cualesquiera sociedades, de modo que los que cambian de una sociedad a otra son los objetos que se consideran tabú y los términos que se utilizan para poder seguir nombrando lo tabú, pero no el tabú mismo” (p. 38). 
Vale la pena recalcar que es en la conversación coloquial donde mejor se evidencia la relación de camaradería entre los miembros de un grupo social, y conviene resaltar que es la solidaridad grupal la que define la aceptación o rechazo de las estrategias elegidas para el intercambio comunicativo. Briz (2000) afirma que:

Es bien sabido que la lengua varía según la situación de uso y según el usuario. Horizontalmente, en la línea de la variedad de uso en situación y en virtud de ciertas condiciones de producción y recepción del discurso, tales como la relación de proximidad entre los participantes, su saber y experiencia compartidos, el grado de cotidianidad, de planificación, la finalidad de la comunicación (interpersonal, transaccional), se distinguen dos registros, el formal y el informal o coloquial (pp. $3-4)$.

Del mismo modo, al interior de cada conglomerado social, las acciones comunicativas giran alrededor de situaciones formales e informales, las cuales definen el registro lingüístico apropiado para el discurso. Desde este punto de vista, se considera a la conversación como la práctica más común entre las personas. En este sentido, el lenguaje juvenil acepta en sus intercambios verbales coloquiales estrategias conversacionales como la ironía, el insulto y ciertas fórmulas de tratamiento, las cuales difieren, según el contexto, de las aceptadas por la mayoría de los adultos. En este orden de ideas, para Van Dijk (1978), la conversación es el evento comunicativo propicio para la construcción de las identidades sociales. Este autor plantea que, para la Sociología, la conversación está estrechamente ligada con la necesidad de reconocer el rol, la función y el estatus de los hablantes, y con las relaciones sociales.

Para el caso de los jóvenes, los ámbitos en que se desarrollan sus interacciones son generalmente informales, lo cual favorece la espontaneidad de las intervenciones y la eventualidad de las estructuras lingüísticas como características de su discurso coloquial. En cuanto a los rasgos distintivos de este tipo de discurso, Bravo y Briz (2004) afirman que: "la regulación y la alternancia de turnos no es rígida, en absoluto está predeterminada y además, los derechos y obligaciones de los participantes se reducen esencialmente a la participación colaborativa, a escuchar y a ser escuchado" (p. 51). Una conversación espontánea entre pares es libre, pero requiere que los interactuantes conozcan y acepten unas regulaciones pragmáticas que facilitan el logro del fin conversacional.

Desde este punto de vista, la tendencia cualitativa del método permite, como lo recalca Albert Gómez (2007), describir e interpretar los fenómenos sociales, en este caso un fenómeno social educativo, identificar las estrategias conversacionales de afinidad e identidad grupal de los adolescentes en actos comunicativos concretos y describir la intención de los hablantes en las interacciones espontáneas. 
Aunque el insulto, como expresión verbal, es un acto de habla que amenaza la imagen del interlocutor, este acto lingüístico, propio de la descortesía, también puede ser usado con la intención de fortalecer la empatía entre los hablantes. El insulto es observable en conversaciones de los adolescentes, en las cuales el registro va cargado de crudeza y espontaneidad, siendo aceptado por quienes lo escuchan, sin presentarse ninguna reacción conflictiva. Por ejemplo:

$B \leftrightarrow$ Ese, ese ese bijueputa del, del, del negro ese $\longrightarrow$ Feo ese bijueputa, ¿no?

$A \leftrightarrow \boldsymbol{H}$ Hy sí, que gonorrea

$B \triangleleft$ Pura jeta de simio ese malparido

$A \leftrightarrow S i$, ino?

$\mathrm{B} \leftrightarrow$ Apenas se asustaba con el Armero ahí... (con acento valluno) hey ve, focalízate mijo!

Los hablantes A y B se refieren aquí a circunstancias deportivas vistas por televisión y lo comentan en un intervalo de clase. Aquí los interactuantes usan el insulto para agredir la imagen de una persona ausente mediante expresiones que descalifican las calidades y origen del afectado. A pesar de ello, no se presentan conflictos ni enfrentamientos entre A y B y, por el contrario, la ofensa al futbolista sirve como una forma de dar por hecho la solidaridad grupal y la camaradería.

Caso contrario ocurre en el siguiente ejemplo:

A: $\uparrow$ Hágase, bobo, marica

D: ((Que le pasaa)).

A: $\uparrow$ Que le pasa a este chino guevón de mierda, cállese, cállese gonorrea, venga a ver bijueputa

(Se acercan y se empujan, pero una docente les bace señas para que se calmen).

En este caso, el hablante A se enfrenta verbalmente al hablante $\mathrm{D}$, debido a que este último le reta con gestos y señas grotescas que A recibe como ofensa directa y su primera forma de salvaguardar su imagen es el insulto verbal.

\section{Conclusión}

Los jóvenes de grado décimo de las dos instituciones estudiadas adaptan de manera natural su lenguaje para acomodarse a las circunstancias contextuales de la conversación, pasando de la descortesía a la cortesía de manera ágil. Teniendo en cuenta que al interior de cada grupo social sus miembros tienen como primer objetivo demostrar la pertenencia 
al mismo y su grado de afiliación, es natural que los hablantes usen estrategias tendientes a la consecución de esa meta. Al respecto, Albelda (2005) reconoce que "Los participantes se influencian mutuamente en sus acciones y representan ante la audiencia 0 ante los coparticipantes determinados papeles que determinan la pauta de acción preestablecida" (p. 93). Las expresiones lingüísticas escuchadas en conversaciones coloquiales, entre estos estudiantes, en escasas circunstancias se consideraron causa de conflicto en la comunicación, ya que estos actos de habla son conocidos y aceptados por todos los participantes y forman parte de su léxico diario en esos espacios donde la actividad grupal es predominante.

Estos enunciados disfemísticos resemantizados, que son disonantes para oyentes ajenos a su comunidad de habla, sirven para fortalecer las relaciones de camaradería y afinidad entre los jóvenes, siempre y cuando no se vea afectada la imagen de los interlocutores, y se usan como llave para pertenecer a un grupo. Ciertos vocablos que antes eran peyorativos, se van cargando positivamente en sus sememas, sin perder su sentido primario y adquiriendo otros nuevos, hasta hacer parte de los hábitos lingüísticos de los jóvenes. Se determina así que las estrategias de afinidad e identidad grupal más arraigadas en los estudiantes del grado décimo son los términos tabúes y las palabras malsonantes.

De otro lado, se pudo constatar que el uso de estrategias de mitigación entre los informantes no es tan frecuente, ya que ellos prefieren ser directos en su forma de comunicarse, la atenuación de sus manifestaciones verbales es uno de sus últimos intereses pragmáticos. Sin embargo, esta categoría de análisis puede surgir en ocasiones en las cuales el destinatario de las expresiones lingüistas disfémicas evidencia disgusto o inconformismo, entonces, el enunciador acude a la atenuación para evitar el deterioro de las relaciones de afinidad.

\section{Referencias bibliográficas}

Albelda Marco, M. (2005). El refuerzo de la imagen social en la conversación coloquial. En D. Bravo (ed.). Cortesía Lingüística y Comunicativa en Español. Categorías conceptuales y aplicaciones a corpus orales y escritos (pp. 93-118). Buenos Aires: Dunken.

Albert, M. (2005). La investigación educativa. Madrid: McGraw-Hill.

Andersson, L., \& Trudgill, P. (1990). Bad Language. Oxford: Penguin Books Ltda.

Arias Bedoya, F. Y., García Romero, M. A., \& Ruiz Villada, A. C. (2016). Fórmulas de tratamiento nominal en la Universidad de Antioquia. Aproximaciones al habla de estudiantes de las Facultades de Educación e Ingeniería. Cuadernos de Lingüística Hispánica, (27), 57-77. Doi: http://dx.doi.org/10.19053/0121053X. 4210 
Baran, M. (2010). Emotividad y convención sociopragmática. Una contribución al estudio del ethos comunicativo de la comunidad hispanobablante peninsular. Polonia: Universidad de Łódź.

Bernal, M. (2007). Categorización sociopragmática de la cortesía y de la descortesía. Un estudio de la conversación coloquial española. Estocolmo: Universidad de Estocolmo.

Bravo, D. (2003). Actividades de cortesía, imagen social y contextos socioculturales una introducción. En D. Bravo (ed.). Actas del Primer Coloquio del Programa Edice (pp. 98-107).

Bravo, D., \& Briz, A. (eds.) (2004). Pragmática sociocultural: estudios sobre el discurso de cortesía en español. Barcelona: Ariel.

Briz, A. (1997). Coherencia y cohesión en la conversación coloquial. Gramma-Temas, 2, 9-44. Valencia, España: Servicio de publicaciones.

Briz, A. \& Grupo Val.Es.Co. (2000). Cómo se comenta un texto coloquial. Barcelona: Ariel.

Calderón Noguera, D., \& Alvarado, J. (2011). El papel de la entrevista en la investigación sociolingüística. Cuadernos de Lingüística Hispánica, (17), 11-24. Recuperado de http:// revistas.uptc.edu.co/revistas/index.php/linguistica_hispa nica/article/view/423

Calsamiglia, H., \& Tusón, A. (2002). Las cosas del decir. Manual de análisis del discurso. Barcelona: Ariel.

Castellano Ascencio, M.D. (2012). Cortesía verbal y fórmulas de tratamiento nominales: Análisis pragmático de las fórmulas de tratamiento nominales en el habla de Medellín. Cuadernos de Lingüística Hispánica, (20), 41-56. Recuperado de http://revistas.uptc.edu.co/revistas/ index.php/linguistica_his panica/article/view/464/464

Díaz, J. (2012). Pragmalingüística del Disfemismo y la Descortesía. (Tesis doctoral). Madrid Universidad Carlos III, Madrid, España. Recuperado de https://www.google.com.co / search?sourceid= chrome.

Duranti, A. (1988). La etnografía del habla: hacia una lingüística de la praxis. En: F. Newmeyer (ed.). Panorama de la Lingüística Moderna (pp. 253-274). Madrid, España: Visor.

Escandell, M. (2004). Aportaciones de la Pragmática. Departamento de Lengua Española y Lingüística General UNED. Recuperado de http://www.textosenlinea.com.ar/textos/ Aportaciones\%20de\%20la\%20pragmatica.pdf.

Fuentes, C., \& Alcaide, E. (2008). Descortesía, agresividad y violencia verbal en la sociedad actual. Sevilla: Universidad Nacional de Andalucía. 
Hernández Flórez, N. (2004). La cortesía como búsqueda del equilibrio de la imagen social. En: D. Bravo \& A. Briz (eds.). Pragmática sociocultural: estudios sobre el discurso de cortesía en español (pp. 95-108). Barcelona: Ariel Lingüística

Hernes, S. (2011). El uso de las palabras tabúes en el lenguaje juvenil de Santiago de Chile y Oslo. Un estudio contrastivo. (Tesis de maestría). Universidad de Bergen, Bergen, Noruega. Recuperado de http://www.colam.org/faksimiler-sider/Ferdig\%20masteroppgave.pdf

Kienpointner, M. (1997). Varieties of rudeness. Types and functions of impolite utterances. Functions of language, 4(2), 251-287.

Kocman, A (2011). La ironía verbal como Semejanza Incongruente. (Tesis doctoral). Universidad de Salamanca, Salamanca, España. Recuperado de http://marcoele.com/descargas/13/ kocman-errores_croatas.pdf.

Labov, W. (1972). Language in the Inner City: Studies in the Black English Vernacular. Oxford: Blackwell.

Lakoff, R. (1973). The logic of politeness; or minding your p's and q's Papers from the 9th Regional Meeting of the Chicago Linguistic Society. Chicago.

Leech, G. (1983). Principles of Pragmátics. New York: Longman Group Ltda.

Leech, G. (2003). Towards an anatomy of politeness in communication. International Journal of Pragmatics, 14, 101-123.

Rundblom, M. (2013). Un estudio del lenguaje soez entre jóvenes en Madrid. ¿Hay diferencias entre géneros? Journal of Pragmatics, 14, 101-123.

Torres Cruz, D.L., \& Hurtado, L.M. (2016). Mecanismos de control que determinan la identidad a través del lenguaje en un contexto escolar. Un estudio para la interacción social. Cuadernos de Lingüística Hispánica , (28), 19-40. doi: http://dx.doi.org/10.19053/0121053X.4906

Tusón, A. (2002). El Análisis de la Conversación: entre la estructura y el sentido. Estudios de sociolingüística, (3), 133-153.

Van Dijk, T. (1978). La ciencia del texto. Un enfoque interdisciplinario. Barcelona: Ediciones Paidós Ibérica.

Velásquez, A. (enero - julio 2007). Lenguaje e identidad en los adolescentes de hoy. Ago, 7(1), 85107. 